\title{
Changes in the $\mathrm{FEV}_{1} / \mathrm{FVC}$ ratio during childhood and adolescence: an intercontinental study
}

\author{
P.H. Quanjer, S. Stanojevic, J. Stocks, G.L. Hall, K.V.V. Prasad, T.J. Cole, \\ M. Rosenthal, R. Perez-Padilla, J.L. Hankinson, E. Falaschetti, M. Golshan, \\ B. Brunekreef, O. Al-Rawas, J. Kühr, Y. Trabelsi and M.S.M Ip on behalf of the \\ Global Lungs Initiative
}

ABSTRACT: In children, the ratio of forced expiratory volume in $1 \mathrm{~s}$ (FEV 1$)$ to forced vital capacity (FVC) is reportedly constant or falls linearly with age, whereas the ratio of residual volume (RV) to total lung capacity (TLC) remains constant. This seems counter-intuitive given the changes in airway properties, body proportions, thoracic shape and respiratory muscle function that occur during growth. The age dependence of lung volumes, FEV $1 / F V C$ and RV/TLC were studied in children worldwide.

Spirometric data were available for 22,412 healthy youths (51.4\% male) aged $4-20$ yrs from 15 centres, and RV and TLC data for 2,253 youths $(56.7 \%$ male) from four centres; three sets included sitting height (SH). Data were fitted as a function of age, height and $\mathrm{SH}$.

In childhood, FVC outgrows TLC and FEV 1 , leading to falls in FEV $1 / F V C$ and RV/TLC; these trends are reversed in adolescence. Taking into account $\mathrm{SH}$ materially reduces differences in pulmonary function within and between ethnic groups. The highest FEV $1 / F V C$ ratios occur in those shortest for their age.

When interpreting lung function test results, the changing pattern in FEV $1 / F V C$ and RV/TLC should be considered. Prediction equations for children and adolescents should take into account sex, height, age, ethnic group, and, ideally, also SH.

KEYWORDS: Ethnicity, growth and development, lung volume measurements, sitting height, thorax

$t$ is generally accepted that the ratio of forced expiratory volume in $1 \mathrm{~s}$ (FEV1) to forced vital capacity (FVC), the established index for diagnosing airway obstruction, decreases from childhood to old age [1, 2]; indeed, it has been shown that infants have larger middle and peripheral airway sizes than are obtained from the proportional downscaling of the adult lung [3], and that lung volumes increase more rapidly than airway calibre in early life [4]. It has also been suggested that the FEV1/FVC ratio falls with both increasing age and body height $(\mathrm{Ht})$ [5-8].

Unlike adulthood, childhood and adolescence represent a period of growth of lung volumes and forced ventilatory flows rather than decay. This growth phase is associated with significant changes in alveolar number and size, the shape and stiffness of the thorax, and muscular strength [9-15]. This potentially affects the total lung capacity (TLC) as well as the FVC, whereas the development of flows, and hence FEV1, is codetermined by airway calibre and the elastic properties of lungs and airways. Thus airway properties, thoracic growth, changes in the mechanical properties of the chest cage and muscular strength interact from birth to early adulthood. During the adolescent growth spurt, this is associated with differences in the timing and rate of growth of lung volumes, flows and body dimensions [16-18]. It, therefore, seems counter-intuitive that the FEV1/FVC ratio should fall linearly with age or Ht during childhood and adolescence [1, 2], as it does in adults, or that the ratio of residual volume (RV) to TLC should remain constant [19].
AFFILIATIONS

For affiliations and details of the Global Lungs Initiative, please see the Acknowledgements section.

CORRESPONDENCE

P.H. Quanjer

Depts of Pulmonary Diseases and Paediatrics, Erasmus Medical Centre Erasmus University Rotterdam

The Netherlands

E-mail: pquanjer@xs4all.n!

Received:

Oct 152009

Accepted after revision:

March 162010

First published online:

March 292010 
Within the framework of the Global Lungs Initiative [20], cross-sectional FEV1, FVC and the FEV1/FVC ratio were examined in males and females in the age range 4-20 yrs from various parts of the world, and a hitherto unknown curvilinear pattern was noted in the latter. This prompted examination of whether this was an artefact arising from collating data from different sources, and, if not, elucidation of possible underlying physiological mechanisms. A unifying mechanism should apply across ethnic groups; therefore, whether patterns differed according to ethnic origin was studied. In order to obtain a more complete picture of lung growth and subdivisions of lung volumes, the available data describing developmental changes in RV, TLC and the RV/ TLC ratio (an index of potential disproportional growth of the vital capacity and the TLC) were also included.

\section{METHODS}

\section{Sitting height}

In three studies, sitting height (SH) was measured either using a Holtain sitting stadiometer (Holtain, Crmwych, UK) or while the subject was seated on a stool placed closely against a wall to which a measuring tape was fixed, with knees flexed at $90^{\circ}$ and flush with the edge of the table or stool on which they sat. The face was gently lifted so that the lower orbital level and the external auditory meatus were level.

\section{Spirometry}

Data from healthy children and adolescents who had been studied in the Netherlands [21, 22], North America (Caucasians, African-Americans and Mexican-Americans) [23], England [8, 24], Germany and Austria [25], Mexico City [6], Iran [7], Oman [26], India [27], Tunisia [28], Hong Kong [29] and Australia (G.L. Hall, Respiratory Medicine, Princess Margaret Hospital, School of Paediatric and Child Health, University of Western Australia, Perth, Australia, personal communication) were collated. All of the studies had received ethical approval from the appropriate governing bodies, and data were collected after written informed consent had been obtained from parents and, where appropriate, the subjects themselves. With the exception of the Australian data, details regarding the selection of subjects, type of equipment used and derivation of summary statistics for FEV1 and FVC have been described previously [6-8, 21-29]. All of the data were derived from children without a history of current or past respiratory disease, and all were lifelong nonsmokers. At least three technically acceptable FVC manoeuvres were obtained, and the largest FEV1, as well as the largest FVC, was reported. The studies complied with guidelines valid at the time of each study [30-33]. The public Third National Health and Nutrition Examination Survey data set used the 1987 American Thoracic Society standards; J.L. Hankinson recalculated the values based on the 1994 standards.

Published data from one study [8] had been limited to individuals aged $\geqslant 16$ yrs; they were complemented with data from those in the 7-16-yr age range that had been collected during the same study using the same protocol and techniques. Three studies comprised longitudinal observations; in one of them [22], a cross-section was constructed by selecting only the first measurement, and, in the other two [16, 25], by selecting a single record from a person's available measurements such that the new cross-sectional data set had an age distribution that was similar to the original data set.

\section{Lung volumes}

Four studies were available with data on RV and TLC. Details of three of the studies have been published [17, 34, 35]. Three of the studies were performed in a whole-body plethysmograph, the remaining one by forced rebreathing using nitrogen as the indicator gas $[36,37]$. In each study, the subjects were free from recent acute or chronic conditions. In the study of ROSENTHAL et al. [34], only data from Caucasian subjects were analysed. In Australian children, data were collected in a body plethysmograph (Vmax AutoBox; SensorMedics, Yorba Linda, CA, USA) according to European Coal and Steel Community/European Respiratory Society standards [31]; the functional residual capacity (FRC) was the mean of the acceptable data: $\mathrm{TLC}=\mathrm{FRC}+$ largest inspiratory capacity; and RV $=\mathrm{TLC}$ - largest slow expiratory vital capacity. Data were collected in a linked fashion: tidal breathing, occlusion with panting, inhalation to TLC and exhalation to RV.

\section{Statistical analysis}

Prior to analysis, the data were checked for transcription errors, improbable values and obvious outliers. Since nearly all of the studies had previously been published, there were very few errors $(<<1 \%)$. Lung function indices were modelled separately in males and females as a function of age, $\mathrm{Ht}, \mathrm{SH}$, where available, and centre of data collection. The model needs to allow for smooth changes across the age range, removing sampling and measurement errors. Generalised additive modelling of location, scale and shape (GAMLSS) was used [38]. This technique offers a choice of distributions, and permits modelling of the median, the coefficient of variation and skewness using cubic smoothing splines. In addition, it permits modelling of additive and multiplicative relationships. All models were fitted using the package GAMLSS [39] in R (version 2.9.1) [40], as described by COLE et al. [41] and recently applied to spirometric reference range data [5]. Further details of the statistical methodology are provided in the online supplementary material.

\section{RESULTS}

Complete data for age, Ht, FEV1, FVC and FEV1/FVC were available for 11,656 males and 10,744 females. Table 1 provides a breakdown by age of the number of individuals. Data on Ht, RV and TLC were available for 1,278 males and 975 females (table 2). Data on $\mathrm{SH}$ were available for children from Hong Kong, England [24] and India for 2,396 males and 1,771 females.

\section{Anthropometry}

Details of the modelling can be found in the online supplementary material. There were small differences in median Ht between Caucasian children of European descent, who were, on average, taller than those in Hong Kong, India, Iran, Oman and Tunisia (table 3). The largest differences occurred in males; thus, at 14 yrs, the median Ht in AsianIndian males was $154.5 \mathrm{~cm}$ compared to $167.4 \mathrm{~cm}$ in US males; for females this equated to 154.4 and $162.1 \mathrm{~cm}$, respectively. The Indian males and females had been classified according to socioeconomic index; details are given in the online supplementary material. 


\begin{tabular}{|c|c|c|c|c|c|c|c|c|c|c|}
\hline \multirow[t]{2}{*}{ Age range yrs } & \multicolumn{10}{|c|}{ Study group } \\
\hline & Cauc & HK & IN & IR & MX & OM & $\mathrm{TN}$ & US2 & US3 & Total \\
\hline \multicolumn{11}{|l|}{ Males } \\
\hline $9-10$ & 1325 & 63 & 298 & 95 & 695 & 92 & 123 & 125 & 102 & 2918 \\
\hline $11-12$ & 1009 & 81 & 295 & 94 & 308 & 62 & 102 & 115 & 119 & 2185 \\
\hline $13-14$ & 533 & 103 & 293 & 84 & 323 & 45 & 38 & 86 & 96 & 1601 \\
\hline $15-16$ & 529 & 79 & 0 & 139 & 218 & 78 & 1 & 131 & 125 & 1300 \\
\hline $17-18$ & 252 & 34 & 0 & 109 & 170 & 57 & 0 & 69 & 48 & 739 \\
\hline $19-20$ & 57 & 0 & 0 & 45 & 83 & 5 & 0 & 17 & 32 & 239 \\
\hline $7-8$ & 1110 & 50 & 262 & 74 & 288 & 54 & 104 & 43 & 51 & 2036 \\
\hline $9-10$ & 1435 & 72 & 206 & 64 & 594 & 60 & 133 & 123 & 86 & 2773 \\
\hline $11-12$ & 957 & 69 & 201 & 59 & 276 & 49 & 78 & 126 & 114 & 1929 \\
\hline $13-14$ & 423 & 105 & 141 & 75 & 295 & 92 & 45 & 113 & 112 & 1401 \\
\hline $15-16$ & 426 & 93 & 0 & 111 & 241 & 120 & 7 & 151 & 135 & 1284 \\
\hline $17-18$ & 177 & 68 & 0 & 86 & 178 & 83 & 0 & 79 & 61 & 732 \\
\hline 19-20 & 64 & 4 & 0 & 33 & 60 & 6 & 0 & 39 & 27 & 233 \\
\hline Total & 4709 & 461 & 995 & 540 & 1932 & 474 & 373 & 674 & 586 & 10744 \\
\hline
\end{tabular}

At all ages, the $\mathrm{SH} / \mathrm{Ht}$ ratio was higher in Chinese than in English children, and lowest in Asian-Indian children (fig. 1).

\section{Spirometry}

Collated data

Overall, the FVC in females was $6.9 \%$ smaller than in males, the FEV $15.0 \%$ smaller and the FEV1/FVC ratio $1.9 \%$ higher. In each of the 15 data sets, FEV1/FVC was related to age and $\mathrm{Ht}$ in both males and females. The FEV1/FVC fell from early childhood to the age associated with the start of the adolescent growth spurt, and then increased again. The median FEV1/FVC in males fell from $\sim 0.96$ at 5 yrs to 0.87 at 11 yrs, before stabilising at $\sim 0.89$ during the teenage years, with a similar pattern in females $(0.96$, 0.89 and 0.91 , respectively). In Caucasian males, the corresponding figures were $0.90,0.86$ and 0.87 , respectively, and, in females, 0.92, 0.88 and 0.90 , respectively. The curvilinear

TABLE 2 Age distribution of males and females with residual volume and total lung capacity data

\begin{tabular}{|c|c|c|c|c|c|c|c|c|c|c|}
\hline \multirow[t]{2}{*}{ Age range yrs } & \multicolumn{5}{|c|}{ Males } & \multicolumn{5}{|c|}{ Females } \\
\hline & $\mathrm{AU}$ & UK2 & HK & NL & Total & AU & UK2 & HK & NL & Total \\
\hline $4-6$ & 1 & 77 & 2 & 0 & 80 & 2 & 24 & 0 & 0 & 26 \\
\hline $7-8$ & 8 & 47 & 29 & 0 & 84 & 9 & 68 & 41 & 0 & 118 \\
\hline $9-10$ & 10 & 15 & 62 & 0 & 87 & 8 & 64 & 77 & 0 & 149 \\
\hline $11-12$ & 17 & 97 & 79 & 47 & 240 & 18 & 71 & 70 & 15 & 174 \\
\hline $13-14$ & 15 & 84 & 102 & 104 & 305 & 15 & 35 & 105 & 32 & 187 \\
\hline $15-16$ & 11 & 90 & 84 & 117 & 302 & 17 & 32 & 91 & 40 & 180 \\
\hline $17-18$ & 3 & 39 & 34 & 97 & 173 & 4 & 15 & 69 & 42 & 130 \\
\hline 19 & 0 & 0 & 0 & 7 & 7 & 1 & 0 & 7 & 3 & 11 \\
\hline Total & 65 & 449 & 392 & 372 & 1278 & 74 & 309 & 460 & 132 & 975 \\
\hline
\end{tabular}

Data are presented as numbers of subjects. AU: Australia; UK2: England [34]; HK: Hong Kong [35]; NL: the Netherlands [17]. 


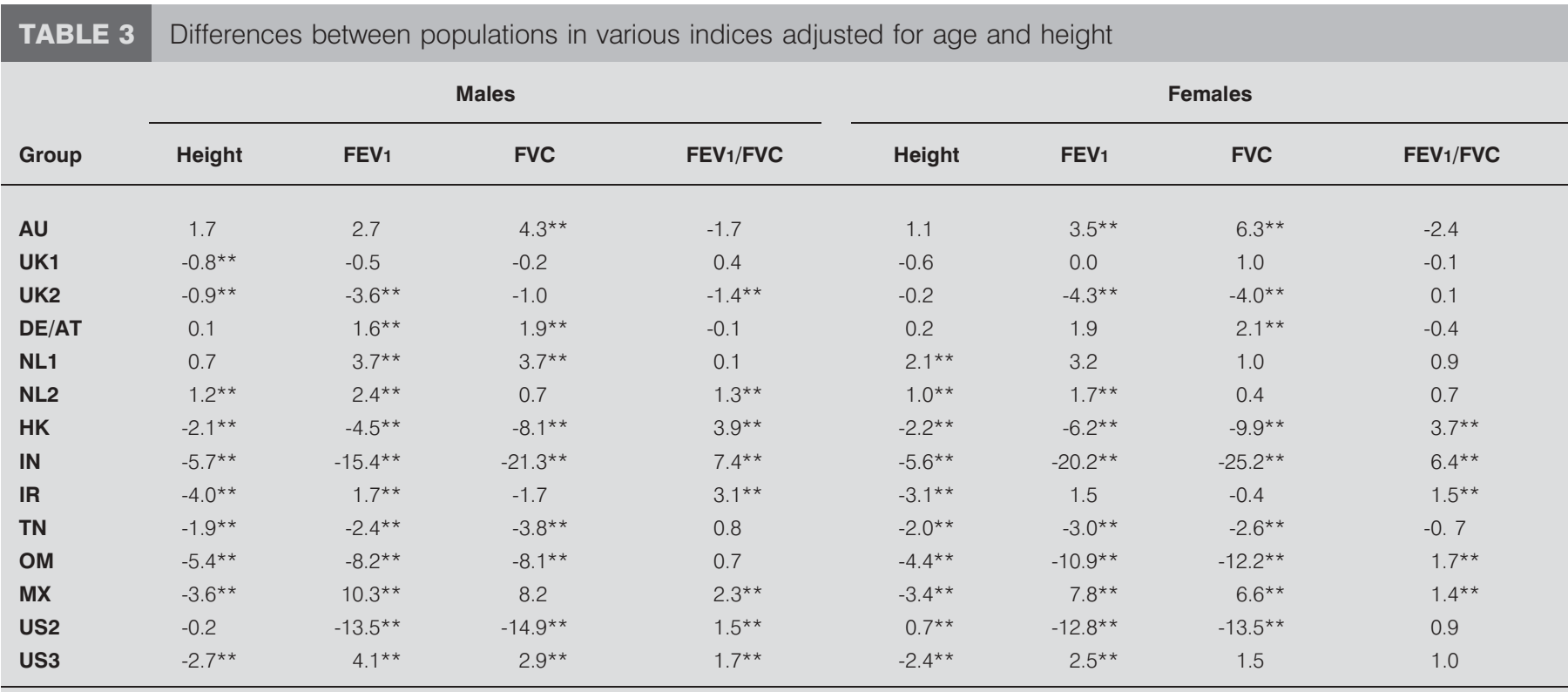

Data are presented as median percentages, and all are compared to US Caucasians (US1) [23]. Proportional differences are shown for height, forced expiratory volume in $1 \mathrm{~s}$ (FEV1), forced vital capacity (FVC) and FEV1/FVC; thus, if the predicted FEV $1 / F V C$ for a US Caucasian male is 0.85 , it is $1.015 \times 0.85=0.86$ for an African-American male. AU: Australia; UK1: England [8]; UK2: England [24]; DE/AT: Germany and Austria [25]; NL1: the Netherlands [21]; NL2: the Netherlands [22]; HK: Hong Kong [29]; IN: India [27]; IR: Iran [7]; TN: Tunisia [28]; OM: Oman [26]; MX: Mexico [6]; US2: African-Americans [23]; US3: Mexican-Americans [23]. **: $p<0.01$ versus US1.

pattern of FEV1/FVC was apparent in the great majority of the data from the different centres (fig. 2). The pattern for the SH/ Ht ratio in each data set, shown for children from Hong Kong in figure 3, was similar to that for FEV1/FVC. The nadir of the curve lagged the FEV1/FVC ratio by $1-2$ y rs, and occurred $1 \mathrm{yr}$ later in males than in females.

\section{Differences between centres}

Between centres, FEV1 and FVC, adjusted for age and Ht, differed significantly in both males and females (table 3). Children in Mexico were exceptional in that a small standing Ht was not associated with a low FEV1 and FVC. The average

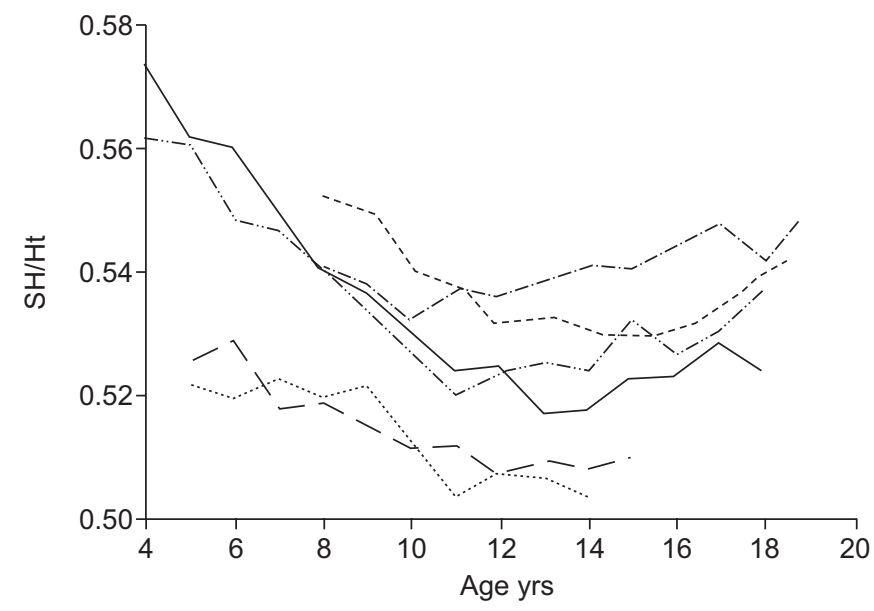

FIGURE 1. Median ratio of sitting height $(\mathrm{SH})$ to height $(\mathrm{Ht})$ as a function of age in English males $(-)$ and females $(-\cdots-\cdots-)$, Asian-Indian males $(----)$ and females (…......), and Hong Kong males (------) and females (- • - · - ).
FEV1/FVC ratio was $0.02-0.06$ higher in males from Hong Kong, India, Iran and Mexico; in females, this was 0.02-0.07 (table 3). The FVC (but not the FEV1) was lowest $(\mathrm{p}<0.005)$, and the FEV1/FVC ratio highest $(\mathrm{p}<0.001)$ in children who were shortest for age (fig. E3 of the online supplementary material). In 13 out of 30 analyses, the ratio was significantly different $(\mathrm{p}<0.01)$ from that found in US Caucasians (US1 data set), an arbitrarily selected comparison group.

\section{Sitting height}

Data on SH were available in children from Hong Kong, India and England. Within data sets, differences between individuals in FEV1 and FVC (in females and in Indian males), but not in FEV1/FVC, were reduced by taking the $\mathrm{SH}$ or $\mathrm{SH} / \mathrm{Ht}$ ratio into account over and above the effects of $\mathrm{Ht}$ and age (see online supplementary material). The same was found in the pooled data, where taking $\mathrm{SH}$ or the $\mathrm{SH} / \mathrm{Ht}$ ratio into account reduced differences in FEV1 and FVC between individuals.

\section{Lung volumes}

TLC was a function of sex, age and Ht. After adjustment for age and $\mathrm{Ht}$, the TLC was $8 \%$ larger in males than in females, and $4.4 \%$ larger in Caucasian than in Chinese children. In Chinese children and in English females, including the $\mathrm{SH}$ or $\mathrm{SH} / \mathrm{Ht}$ ratio significantly improved the fit to the data (see online supplementary material). The RV/TLC ratio was independent of the $\mathrm{SH} / \mathrm{Ht}$ ratio. Until adolescence, the FEV1 increased proportionally more than the TLC; conversely, the RV/TLC ratio fell until the start of adolescence, and then rose (fig. 4).

\section{Comparison with other prediction equations}

Figure 5 shows predicted FEV1/FVC in Caucasians from the present study, constructed using median Ht for age, compared 

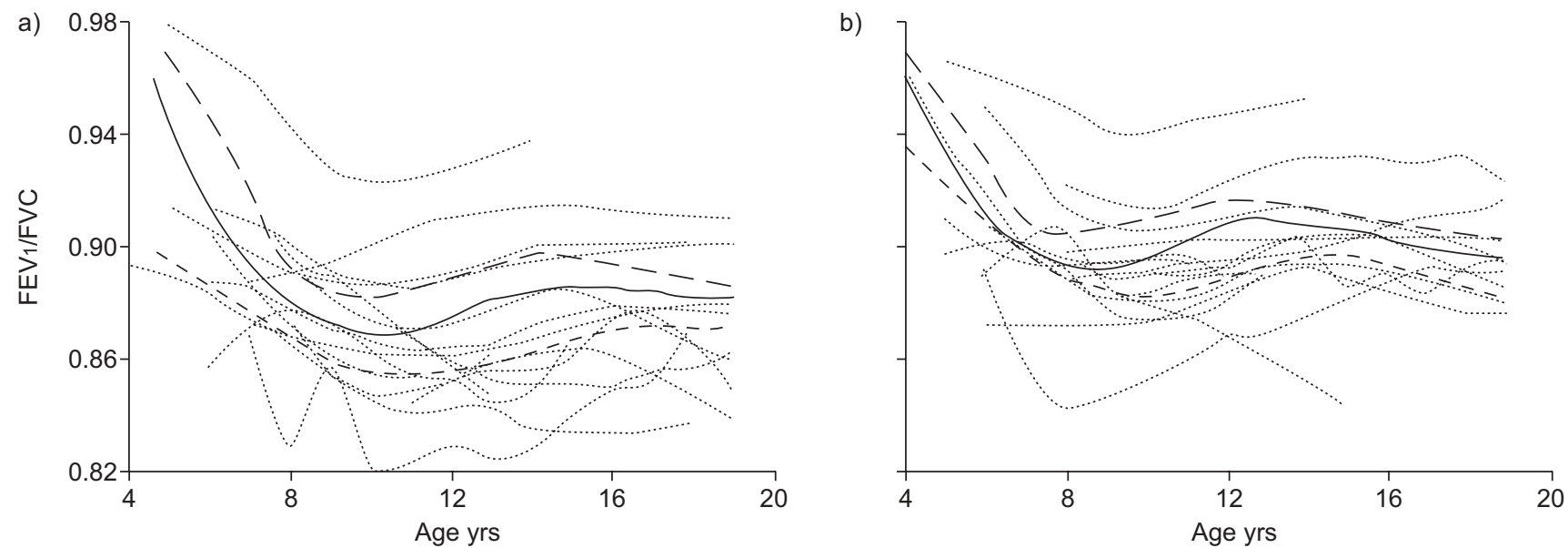

FIGURE 2. Median forced expiratory volume in $1 \mathrm{~s}$ (FEV1)/forced vital capacity (FVC) ratio in 15 data sets (……..) in: a) males; and b) females. Smooth lines were interpolated between points (_ $\_$: median of the 15 data sets; ------: median for Caucasians; - - - -: median for non-Caucasians). The most irregular patterns occurred in the smallest data sets.

with that from recent equations from J.L. Hankinson (1999), J. Kivastik (2001), P.H. Quanjer (1995), M. Rosenthal (1993) and X. Wang (1993) (equations in [2]). One set (X. Wang) had a pattern very similar to that in the present study. Particularly in the oldest males, predicted values tended to be $3-5 \%$ higher than those recommended for use in the USA (J.L. Hankinson) and the UK (M. Rosenthal).

\section{DISCUSSION}

\section{Spirometry and lung volumes}

As the lungs and airways grow during childhood and adolescence, the FVC increases proportionately more than the FEV1 until about the start of the adolescent growth spurt. In Caucasian males, this leads, on average, to a fall in the FEV1/FVC ratio from 0.90 at age 5 yrs to 0.86 at age 11 yrs, followed by a rise to 0.87 in adolescence; in females, this ratio was consistently 0.03 higher (fig. 4). This pattern was observed

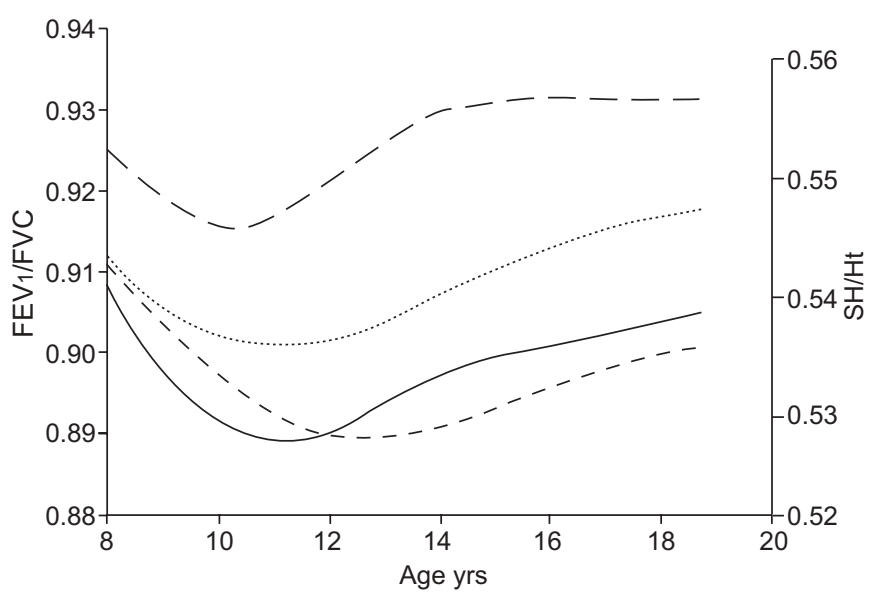

FIGURE 3. Median forced expiratory volume in $1 \mathrm{~s}(\mathrm{FEV} 1$ )/forced vital capacity (FVC) in males (- ${ }^{-}$and females $(----)$and sitting height $(\mathrm{SH}) /$ height $(\mathrm{Ht})$ ratio in males (------) and females (..........) as a function of age in children from Hong Kong [29]. Smooth curves were obtained using cubic splines. The same pattern was observed in data from England [34] and India [27]. in most data sets (fig. 2), and, therefore, cannot be simply attributed to an artefact arising from the collation of different data sets. Findings from the literature are further confirmed (see [42] and references therein), and it was demonstrated that, throughout childhood and adolescence, males have $7-8 \%$ larger lungs, but females have faster lung emptying rates (shorter expiratory time constants), judged from the FEV1/ FVC ratio. The RV/TLC ratio showed a similar curvilinear pattern to that of FEV1/FVC (fig. 4). These novel findings illustrate that the FVC initially increases proportionally more than the TLC and FEV1, and then proportionally less from about the start of the adolescent growth spurt. During that same period, the FEV1 first increases faster than the TLC, and subsequently more slowly (fig. 4). The $\mathrm{SH} / \mathrm{Ht}$ ratio shows the same pattern, but is out of phase by 1-2 yrs (fig. 3). In keeping with the earlier onset of the adolescent growth spurt in females [16-18], the pattern in males is shifted by $1-2$ yrs (fig. 3). These findings show that the development of the FEV1, FVC and TLC are governed by different mechanisms during growth and maturation.

The simplest explanation for these findings is that young children lack the coordination to deliver a full vital capacity, and so they inhale insufficiently or terminate the expiratory effort prematurely, often in $\leqslant 1 \mathrm{~s}$. However, children have been shown to be capable of performing acceptable FVC manoeuvres $[43,44]$, and the results obtained for this analysis were regarded as acceptable by experienced professionals. Moreover, these findings are biologically plausible if the normal growth of lungs and chest is taken into account. During the first years of life, both the number and size of the alveoli increase, which are likely to lead to a faster increase in lung volume $[3,4]$ than in airway calibre $[42,45]$. Thus the FEV1/FVC and RV/TLC ratio fall in early childhood. Maximum respiratory pressures increase with age in schoolchildren $[9,10]$, but not in adolescents [11], and they are higher in males than in females. The increasing inspiratory and expiratory pressures increase vital capacity at the expense of RV. In addition, the greater pressure generated by males explains, at least in part, the difference in vital capacity, and 

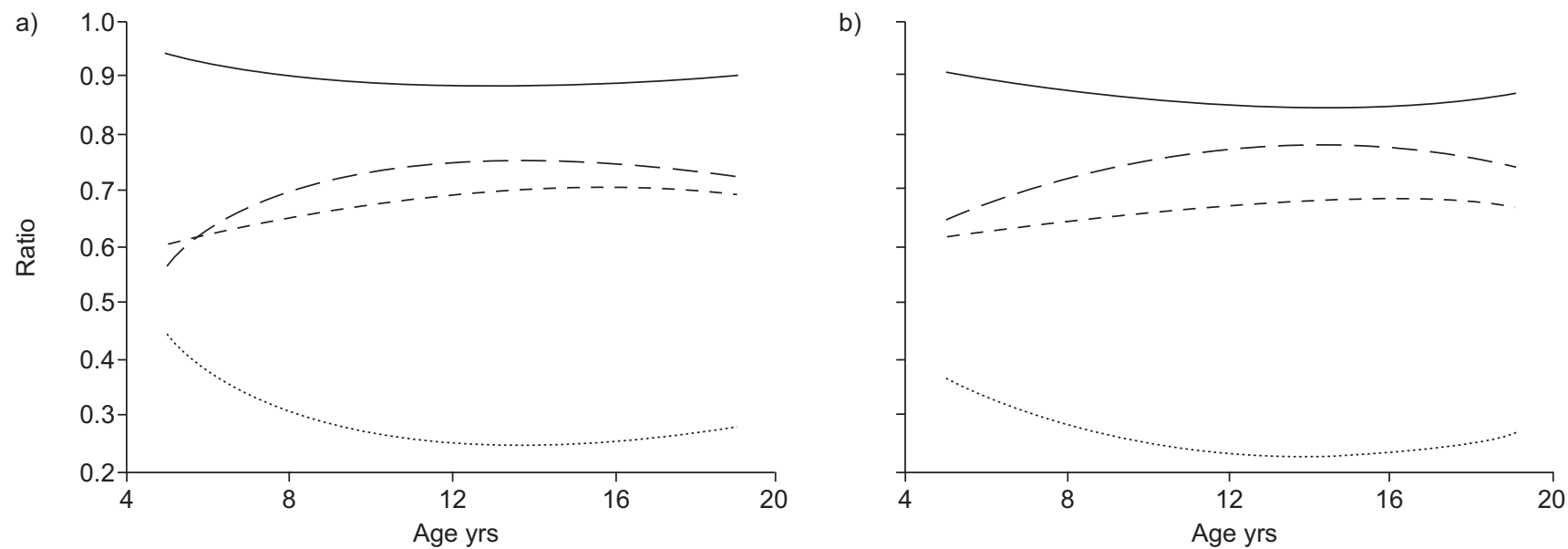

FIGURE 4. Cross-sectional forced expiratory volume in $1 \mathrm{~s}$ relative to forced vital capacity (FVC) $(-$ ) and total lung capacity (TLC) (------), and of FVC (----) and residual volume (…....) relative to TLC in Caucasian: a) males $(n=886)$; and b) females $(n=515)$ from Australia, the Netherlands [17, 21] and England [34].

hence in FEV1/FVC and RV/TLC ratio, between males and females.

\section{Changes in the chest cage during growth}

Significant changes occur in the configuration of the thorax (fig. E2 of online supplementary material). From infancy to early adult life, there is progressive drooping of the thoracic cage, the sternum and sternal ends of the ribs taking up lower positions relative to the vertebrae; in addition, the level of the domes of the diaphragm descends to below the anterior end of the fifth rib $[12,15]$. The thorax becomes elongated and more slender as thoracic width increases proportionately less than $\mathrm{Ht}$. In males, thoracic width and $\mathrm{Ht}$ still increase during adolescence; in females, this is limited to lung Ht [13, 14], leaving the adolescent female's chest more slender than that of males. Thus the functional and morphological changes, which near completion at the start of puberty, contribute to development of a proportionately larger vital capacity from childhood to the adolescent growth spurt. Subsequently the gradual stiffening of the respiratory system between birth and age 18 yrs [46] starts to limit full expirations.

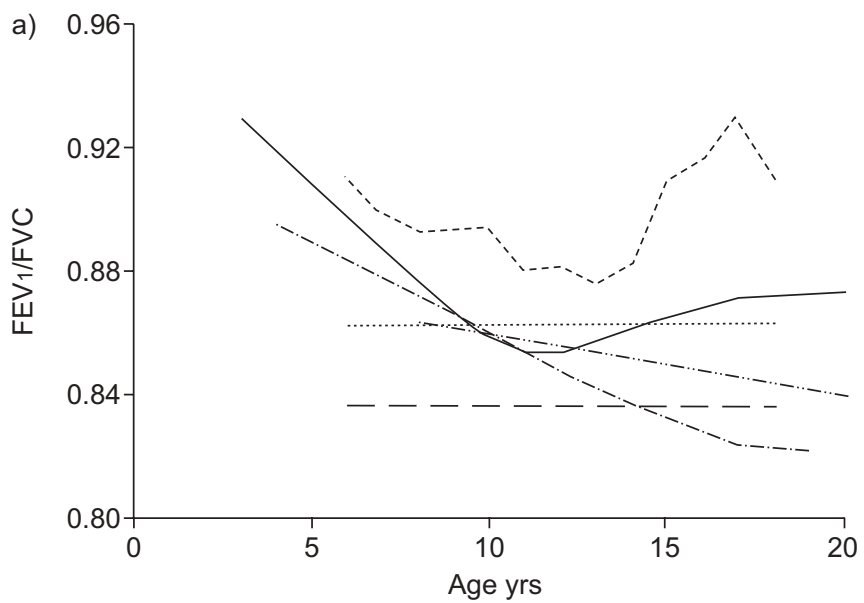

\section{Anthropometry and ethnicity}

Differences in lung volumes in persons of the same Ht can be accounted for by differences in chest dimensions, as partially reflected in the $\mathrm{SH} / \mathrm{Ht}$ ratio; in two recent studies, ethnic differences in lung function were thus reduced by up to $50 \%$ after accounting for $\mathrm{SH}[47,48]$. In the present study, in ethnically homogeneous groups, taking the $\mathrm{SH} / \mathrm{Ht}$ ratio, in addition to age and $\mathrm{Ht}$, into account consistently reduced differences in pulmonary function between females; in males, the findings were less consistent (see online supplementary material). In mixed ethnic groups, taking into account the $\mathrm{SH}$ or $\mathrm{SH} / \mathrm{Ht}$ ratio led to a pronounced improvement in the fit to the data. By contrast, any differences in the $\mathrm{SH} / \mathrm{Ht}$ ratio between individuals are cancelled out when pulmonary function indices are expressed as ratios, the FEV1/FVC and RV/TLC ratio being solely dependent upon sex, age and Ht.

In early childhood, the trunk grows proportionately less than the legs (figs. 1 and 2) so that lung growth is less than expected from the increase in Ht. Conversely, during adolescence, growth in standing $\mathrm{Ht}$ is associated with a rising $\mathrm{SH} / \mathrm{Ht}$ ratio,

b)

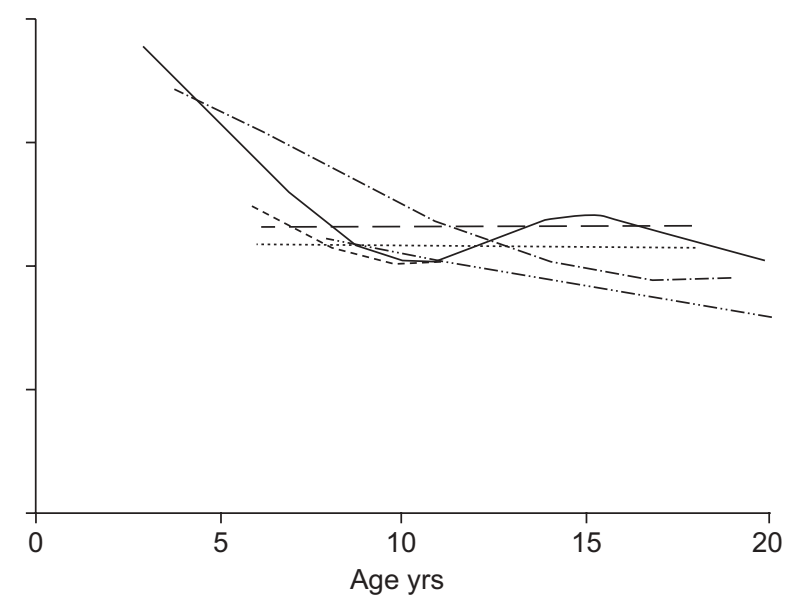

FIGURE 5. Comparison between forced expiratory volume in $1 \mathrm{~s} \mathrm{(FEV1)/forced} \mathrm{vital} \mathrm{capacity} \mathrm{(FVC)} \mathrm{according} \mathrm{to} \mathrm{the} \mathrm{present} \mathrm{analysis} \mathrm{(} \longrightarrow$ ) and according to J.L. Hankinson $(-\cdot-\cdot--)$, J. Kivastik (--- ), P.H. Quanjer (…….), M. Rosenthal $(-\cdot-\cdot-)$ and X. Wang (------) (prediction equations in [2]) in: a) males; and b) females. 
hence the rise in lung volumes at this age is bound to be greater than predicted from $\mathrm{Ht}$ alone. Therefore, standing $\mathrm{Ht}$ alone cannot satisfactorily predict lung volumes; adding age, and, in many cases, also the $\mathrm{SH} / \mathrm{Ht}$ ratio, reduced this effect.

If ethnic differences in FEV1 and FVC are proportional, the FEV1/FVC ratio should be the same for different ethnic groups. However, children from India, Iran, Mexico and Oman were systematically shorter than Caucasians and yet had the highest FEV1/FVC ratios (table 3 and fig. E3 of online supplementary material). This may well reflect differences in developmental age between populations [49] and/or nutritional status; data on pubertal stage were unavailable and we, therefore, cannot estimate how much this may have contributed to the observed differences. We have, however, previously reported that the multiplicative modelling of $\mathrm{Ht}$ and age can act as a proxy for puberty, in that those children who are short for their age (and have generally not gone through puberty) have a lower predicted FVC and hence FEV1/FVC [5, 50]. Asian-Indian children with the lowest socioeconomic index, whose short stature and low body mass index were evidence of stunted growth (see online supplementary material for details), produced, on average, the highest FEV1/FVC ratios. The FEV1 is a time-averaged flow, which is, for the most part, governed by airway calibre and the elastic properties of lungs and airways [51], and is, therefore, only indirectly affected by factors that limit lung expansion. All this is compatible with the present finding that shorter stature, whether due to differences in the age of onset of maturation or stunted growth, affects vital capacity disproportionately (fig. 4).

The present study was not undertaken to derive prediction equations, or to analyse differences due to technical or procedural factors. Such differences may account for some of the differences observed between centres. However, the availability of data from many centres and ethnic groups provided a unique opportunity to study patterns of lung growth in various parts of the world, rather than the absolute level of pulmonary function, as is more commonly reported. Even if the quality of measurements between centres differed, the consistent pattern is strong evidence of an underlying physiological mechanism. As in the study of STANOJEVIC et al. [5], with the exception of English children, Caucasian children from different centres produced a higher FEV1 and FVC than their American counterparts (table 3). Mexican children produced relatively large volumes (table 3), possibly because they were born and raised at an altitude of 2,240 $\mathrm{m}$ [52]. In spite of a comparable TLC for Ht and age between children from Hong Kong, Australia, the Netherlands and England, the RV/TLC ratio was appreciably smaller in Australian youths, who had a larger vital capacity, for which we have no explanation.

It is concluded that the use of appropriate modelling techniques discloses that the FEV1/FVC and RV/TLC ratio follow a curvilinear pattern from childhood to adulthood. This can be explained by differences in the development of airway properties, body dimensions, chest shape and respiratory muscle function during growth; these first facilitate growth of the FVC relative to the FEV1 and TLC, but limit its growth during adolescence. Thus the FEV1/FVC ratio in Caucasian children falls by $\sim 5 \%$ during childhood, and then increases by $\sim 2 \%$ during adolescence. These findings are quite different from those of commonly used prediction equations, and, therefore, have a bearing on the interpretation of pulmonary function test results in children and adolescents (fig. 5). Future studies of predicted values, such as the Global Lungs Initiative [20], should consider these important age-related changes. Taking into account $\mathrm{SH}$ diminishes differences between individuals, particularly in ethnically mixed groups, and has rarely been undertaken in the past. Secular trends in body dimensions $[53,54]$ potentially affect thoracic dimensions, and may alter findings in the offspring of different ethnic groups, thus leading to secular trends in pulmonary function [29]; more research is required in order to identify variables that can be easily measured in a clinical setting, reflecting body shape, proportions and composition that help to explain differences between subjects, and obviate the need for ethnic-specific reference equations.

\section{STATEMENT OF INTEREST}

None declared.

\section{ACKNOWLEDGEMENTS}

The affiliations of the present authors are as follows. P.H. Quanjer: Depts of Pulmonary Diseases and Paediatrics, Erasmus Medical Centre, Erasmus University, Rotterdam; and B. Brunekreef: Institute for Risk Assessment Sciences, Utrecht University, Utrecht, and Julius Center for Health Sciences and Primary Care, University Medical Center Utrecht, Utrecht (all the Netherlands). S. Stanojevic and T.J. Cole: Medical Research Council Centre of Epidemiology for Child Health, UCL Institute of Child Health; J. Stocks: Portex Respiratory Unit, UCL Institute of Child Health; E. Falaschetti: Dept of Epidemiology and Public Health, University College London; and M Rosenthal: Royal Brompton Hospital (all London, UK). G.L. Hall: Respiratory Medicine, Princess Margaret Hospital for Children, and School of Paediatric and Child Health, University of Western Australia (both Perth, Australia). K.V.V. Prasad: Government Vemana Yoga Research Institute, Ameerpet, India. R. Perez-Padilla: National Institute of Respiratory Diseases, Mexico, Mexico. J.L. Hankinson: Hankinson Consulting, Valdosta, GA, USA. M. Golshan: Dept of Medicine, Isfahan University of Medical Sciences, Isfahan, Iran. O. Al-Rawas: Dept of Medicine, College of Medicine and Health Sciences, Sultan Qaboos University, Muscat, Oman. J. Kühr: Klinik für Kinder- und Jugendmedizin, Zentrum für Kinder und Frauen, Kinderklinik Städtisches Klinikum Karlsruhe, Karlsruhe, Germany. Y. Trabelsi: Université de Sousse, Laboratoire de Physiologie et des Explorations Fonctionnelles, Faculté de Médecine de Sousse, Sousse, Tunisia. M.S.M. Ip: Dept of Medicine, The University of Hong Kong, Pokfulam, Hong Kong SAR, China.

The Global Lungs Initiative aims to collate international pulmonary function data with the objective of deriving predicted values from childhood to old age that are valid worldwide [20]; this initiative has been adopted by the European Respiratory Society as a Task Force (new lung function reference values: a united approach; TF-2009-03). Active members of the Global Lungs Initiative: O.A. Al-Rawas: College of Medicine and Health Sciences, Sultan Qaboos University, Muscat, Oman; M. Badier: Saint Marguerite Hospital, Marseille, France; X. Baur (cochair): Institute for Occupational and Maritime Medicine, University Medical Center Hamburg-Eppendorf, Hamburg, Germany; C. Beardsmore: Dept of Infection, Immunity and Inflammation (Child Health), University of Leicester, Leicester, UK; B. Brunekreef: Institute for Risk Assessment Sciences, Utrecht University, Utrecht, the Netherlands; B. Culver B (co-chair): Division of Pulmonary and Critical Care Medicine, Dept of Medicine, University of Washington, Seattle, WA, USA 
T.J. Cole: Medical Research Council Centre of Epidemiology for Child Health, University College London Institute of Child Health, London, UK; A. Custovic: National Institute for Health Research Translational Research Facility in Respiratory Medicine, University of Manchester, Manchester, UK; W. Dejsomritrutai: Dept of Medicine, Faculty of Medicine, Siriraj Hospital, Mahidol University, Bangkok, Thailand; H. Eigen: Riley Hospital for Children, Section of Pediatric Pulmonology, Indianapolis, IN, USA; P.L. Enright: The University of Arizona, Tucson, AZ, USA; E. Falaschetti: Vascular Physiology Unit, Institute of Child Health, London, UK; B. Fallon: Respiratory Laboratory, Nepean Hospital, Penrith, Australia; A. Fulambarker: Pulmonary Division, Rosalind Franklin University of Medicine and Science/The Chicago Medical School, Chicago, IL, USA; M. Gerbase-Weidenbach: Division of Pulmonary Medicine, University Hospitals of Geneva, Geneva, Switzerland; M. Gappa: Klinik für Kinder-und Jugendmedizin, Marien-Hospital Wesel, Wesel, Germany; M. Golshan: Bamdad Respiratory Research Institute, Isfahan, Iran; C. Gore: Physiology Dept, Australian Institute of Sport, Belconnen, Australia, G.L. Hall (co-chair): Respiratory Medicine, Princess Margaret Hospital, School of Paediatric and Child Health, University of Western Australia, Perth, Australia; J.L. Hankinson: Hankinson Consulting, Valdosta, GA, USA; J. Henderson: Avon Longitudinal Study of Parents and Children, University of Bristol, Bristol, UK; M.S.M. Ip: Dept of Medicine, The University of Hong Kong, Pokfulam, Hong Kong, China; M. Jones: Hospital São Lucas Pontifícia Universidade Católica do Rio Grande do Sul, Division of Pediatric Pulmonology, Porto Alegre, Brazil; G. Kerby: University of Colorado Denver School of Medicine, Pulmonary Medicine, The Children's Hospital, Aurora, CO, USA; J. Kirkby: University College London Institute of Child Health, London, UK; J. Kühr: Klinik für Kinder-und Jugendmedizin, Zentrum für Kinder und Frauen, Kinderklinik, Städtisches Klinikum Karlsruhe, Karlsruhe, Germany; S. Kuster: Lungenliga Zürich, Zurich, Switzerland; A. Langhammer: Nord-Trøndelag Health Study Research Centre, Norwegian University of Science and Technology, Verdal, Norway; S. Lum: Portex Respiratory Unit, University College London Institute of Child Health, London, UK; A. Miller: MannKind Corporation, Paramus, NJ, USA; W. Nystad, Division of Epidemiology, Norwegian Institute of Public Health, Oslo, Norway; Y.M. Oh: Dept of Pulmonary and Critical Care Medicine, Asan Medical Center, University of Ulsan College of Medicine, Seoul, South Korea; W-H. Pan: Institute of Biomedical Sciences, Academica Sinica, Taipei, Taiwan; R. PerezPadilla: Instituto Nacional de Enfermedades Respiratorias, Mexico City, Mexico; P. Piccioni: SC Pneumologia CPA, Azienda Sanitaria Locale 4 Torino, Turin, Italy; F. Pistelli: Dipartimento Cardio-Toracico, Unità Operativa di Pneumologia e Fisiopatologia Respiratoria Universitaria, Azienda Ospedaliero-Universitaria Pisana, Pisa, Italy; K.V.V. Prasad: Dept of Physiology, Vemana Yoga Research Institute, Hyderabad, India; P.H. Quanjer: Depts of Pulmonary Diseases and Paediatrics, Erasmus Medical Centre, Erasmus University, Rotterdam, the Netherlands; M. Rosenthal, Dept of Paediatric Respiratory Medicine, Royal Brompton Hospital, London, UK; J. Soriano: Program of Epidemiology and Clinical Research, Fundación CaubetCIMERA Illes Balears, Recinte Hospital Joan March, Bunyola, Spain; S. Stanojevic: Portex Respiratory Unit, University College London Institute of Child Health, London, UK; J. Stocks (co-chair): Portex Respiratory Unit, University College London Institute of Child Health, London, UK; F. Thomas: Investigations Préventives et Cliniques, Paris, Ile de France, Paris, France; W. Tomalak: Institute for Tuberculosis and Lung Diseases, Rabka, Poland; Y. Trabelsi: Laboratoire de Physiologie et des Explorations Fonctionnelles, Faculté de Médecine de Sousse, Sousse, Tunisia; S. Turner: Academic Child Health, University of Aberdeen, Aberdeen, UK; D. Vilozni: Edmond and Lili Safra Children's Hospital, Sheba Medical Center, Tel Hashomer, Israel; H. Vlachos-Mayer: Division of Respiratory Medicine, Dept of Pediatrics, Centre Hospitalier Universitaire de Sherbrooke-Hôpital Fleurimont, University of Sherbrooke, Sherbrooke, Canada; S. West: Respiratory Function Laboratory,
Westmead Hospital, Westmead, Australia; D. Zagami: Lung Function Laboratory, Gold Coast Hospital, Southport, Australia; and J.P. Zheng: State Key Laboratory of Respiratory Disease, First Affiliated Hospital of Guangzhou Medical University, Guangzhou, China.

\section{REFERENCES}

1 Quanjer PH, Stocks J, Polgar G, et al. Compilation of reference values for lung function measurements in children. Eur Respir J 1989; 2: Suppl. 4, 184s-216s.

2 SpirXpert. Become an Expert in Spirometry. www.spirxpert.com/ GOLD.html Date last updated: March 12, 2010. Date last accessed: May 16, 2010.

3 Lambert RK, Castile RG, Tepper RS. Model of forced expiratory flows and airway geometry in infants. J Appl Physiol 2004; 96: 688-692.

4 Tepper RS, Jones M, Davis S, et al. Rate constant for forced expiration decreases with lung growth during infancy. Am J Respir Crit Care Med 1999; 160: 835-838.

5 Stanojevic S, Wade A, Cole TJ, et al. Spirometry centile charts for young Caucasian children: the Asthma UK Collaborative Initiative. Am J Respir Crit Care Med 2009; 180: 547-552.

6 Pérez-Padilla R, Regalado-Pineda J, Rojas M, et al. Spirometric function in children of Mexico City compared to MexicanAmerican children. Pediatr Pulmonol 2003; 35: 177-183.

7 Golshan M, Nematbakhsh M, Amra B, et al. Spirometric reference values in a large Middle Eastern population. Eur Respir J 2003; 22: 529-534.

8 Falaschetti E, Laiho J, Primatesta P, et al. Prediction equations for normal and low lung function from the Health Survey for England. Eur Respir J 2004; 23: 456-463.

9 Gaultier C, Zinman R. Maximal static pressures in healthy children. Respir Physiol 1983; 21: 45-61.

10 Tomalak W, Pogorzelski A, Prusak J. Normal values for maximal static inspiratory and expiratory pressures in healthy children. Pediatr Pulmonol 2002; 34: 42-46.

11 Schrader PC, Quanjer PH, Olievier ICW. Respiratory muscle force and ventilatory function in adolescents. Eur Respir J 1988; 1: 368-375.

12 Simon G, Reid L, Tanner JM, et al. Growth of radiologically determined heart diameter, lung width and lung length from 519 years, with standards for clinical use. Arch Dis Child 1972; 47: 373-381.

13 Tanner JM. Growth at Adolescence. 2nd Edn. Oxford, Blackwell, 1962.

14 Degroodt EG, van Pelt W, Borsboom GJJM, et al. Growth of lung and thorax dimensions during the pubertal growth spurt. Eur Respir J 1988; 1: 102-108.

15 Grivas TB, Burwell RG, Purdue M, et al. A segmental analysis of thoracic shape in chest radiographs of children. Changes related to spinal level, age, sex, side and significance for lung growth and scoliosis. J Anat 1991; 178: 21-38.

16 Schrader PC, Quanjer PH, van Zomeren BC, et al. Changes in the FEV1-height relationship during pubertal growth. Bull Eur Physiopathol Respir 1984; 20: 381-388.

17 Degroodt EG, Quanjer PH, Wise ME, et al. Changing relationships between stature and lung volumes during puberty. Respir Physiol 1986; 65: 139-153.

18 Hibbert M, Lannigan A, Raven J, et al. Gender differences in lung growth. Pediatr Pulmonol 1995; 19: 129-134.

19 Stocks J, Quanjer PH. Reference values for residual volume, functional residual capacity and total lung capacity. ATS workshop on lung volume measurements. Official statement of the European Respiratory Society. Eur Respir J 1995; 8: 492-506. 
20 Global Lungs Initiative. Lung Function in Growth and Aging: a United Worldwide Approach. www.lungfunction.org Date last updated: July 20, 2010. Date last accessed: July 20, 2010.

21 Schrader PC, Quanjer PH, van Zomeren BC, et al. Selection of variables from maximum expiratory flow-volume curves. Bull Eur Physiopathol Respir 1983; 19: 43-49.

22 Smeets M, Brunekreef B, Dijkstra L, et al. Lung growth of preadolescent children. Eur Respir J 1990; 3: 91-96.

23 Hankinson JL, Odencrantz JR, Fedan KB. Spirometric reference values from a sample of the general US population. Am J Respir Crit Care Med 1999; 159: 179-187.

24 Rosenthal M, Bain SH, Cramer D, et al. Lung function in white children aged 4-19 years: I - Spirometry. Thorax 1993; 48: 794-802.

25 Baars JC, Ihorst G, Forster J, et al. Lungenfunktionsreferenzwerte im Schulalter. [Lung function reference data in school-age children.] Pneumologie 2001; 55: 72-78.

26 Al-Riyami BM, Al-Rawas OA, Hassan MO. Normal spirometric reference values for Omani children and adolescents. Respirology 2004; 9: 387-391.

27 Sitarama Raju P, Prasad KVV, Venkata Ramana Y, et al. Influence of socioeconomic status on lung function and prediction equations in Indian children. Pediatr Pulmonol 2005; 39: 528-536.

28 Trabelsi $Y$, Ben Saad H, Tabka Z, et al. Spirometric reference values in Tunisian children. Respiration 2004; 71: 511-518.

29 Ip MSM, Karlberg EM, Karlberg JPE, et al. Lung function reference values in Chinese children and adolescents in Hong Kong. I. Spirometric values and comparison with other populations. Am J Respir Crit Care Med 2000; 162: 424-429.

30 Quanjer PH, Tammeling GJ, Cotes 1E., et al, Lung volumes and forced ventilatory flows. Eur Respir J 1993; 6: Suppl. 16, 5-40.

31 Quanjer $\mathrm{PH}$, ed, Standardized Lung Function Testing. Report Working Party "Standardization of Lung Function Tests", European Community for Coal and Steel. Bull Eur Physiopath Respir 1983; 19: Suppl. 5, 1-95.

32 Anon, Standardization of spirometry, 1994 update. American Thoracic Society. Am J Respir Crit Care Med 1995; 152: 1107-1136.

33 Anon, Standardization of spirometry - 1987 update. Statement of the American Thoracic Society. Am Rev Respir Dis 1987; 136: $1285-1298$.

34 Rosenthal M, Cramer D, Bain SH, et al. Lung function in white children aged 4 to 19 years: II - Single breath analysis and plethysmography. Thorax 1993; 48: 803-808.

35 Ip MS, Karlberg EM, Chan KN, et al. Lung function reference values in Chinese children and adolescents in Hong Kong: II. Prediction equations for plethysmographic lung volumes. Am J Respir Crit Care Med 2000; 162: 430-435.

36 Sterk PJ, Quanjer PH, van der Maas LLJ, et al. The validity of the single breath nitrogen determination of residual volume. Bull Eur Physiopathol Respir 1980; 16: 195-213.
37 Merkus PJFM, Verver S, van Essen-Zandvliet EEM, et al. Lung volumes measured by the forced rebreathing technique in children with airways obstruction. Eur Respir J 1992; 5: 879-886.

38 Rigby RA, Stasinopoulos DM. Generalized additive models for location, scale and shape. J R Stat Soc Ser C Appl Stat 2005; 54 507-544.

39 Stasinopoulos M. GAMLSS. www.gamlss.com Date last updated: May 27, 2010. Date last accessed: June 20, 2010.

40 R Development Core Team, R: A Language and Environment for Statistical Computing. Vienna, R Foundation for Statistical Computing, 2008.

41 Cole TJ, Stanojevic S, Stocks J, et al. Age- and size-related reference ranges: a case study of spirometry through childhood and adulthood. Stat Med 2009; 28: 880-898.

42 Merkus PJ, ten Have-Opbroek AA, Quanjer PH. Human lung growth: a review. Pediatr Pulmonol 1996; 21: 383-397.

43 D'Angelo E, Carnelli V, D'Angelo E, et al. Performance of forced expiratory manoeuvre in children. Eur Respir J 2000; 16: 1070-1074.

44 Vilozni D, Hakim F, Adler A, et al. Reduced vital capacity after methacholine challenge in early childhood - is it due to trapped air or loss of motivation. Respir Med 2009; 103: 109-116.

45 Ochs M, Nyengaard JR, Jung A, et al. The number of alveoli in the human lung. Am J Respir Crit Care Med 2004; 169: 120-124.

46 Sharp JT, Druz WS, Balagot RC, et al. Total respiratory compliance in infants and children. J Appl Physiol 1970; 29: 775-779.

47 Harik-Khan RFI, Muller DC, Wise RA. Racial difference in lung function in African-American and white children: effect of anthropometric, socioeconomic, nutritional, and environmental factors. Am J Respir Epidemiol 2004; 160: 893-900.

48 Whitrow MJ, Harding S. Ethnic differences in adolescent lung function. Anthropometric, socioeconomic, and psychological factors. Am J Respir Crit Care Med 2008; 177: 1262-1267.

49 Wu T, Mendola P, Buck GM. Ethnic differences in the presence of secondary sex characteristics and menarche among US girls: the Third National Health and Nutrition Examination Survey, 19881994. Pediatrics 2002; 110: 752-757.

50 Stanojevic S, Wade A, Stocks J, et al. Reference ranges for spirometry across all ages. A new approach. Am J Respir Crit Care Med 2008; 177: 253-260.

51 Dawson SV, Elliott EA. Wave-speed limitation on expiratory flow: a unifying concept. J Appl Physiol 1977; 43: 498-515.

52 Greksa LP, Spielvogel H, Paz-Zamora M, et al. Effect of altitude on the lung function of high altitude residents of European ancestry. Am J Phys Anthropol 2005; 75: 77-85.

53 Tanner JM, Hayashi T, Preece MA, et al. Increase in length of leg relative to trunk in Japanese children and adults from 1957 to 1977: comparison with British and with Japanese Americans. Ann Hum Biol 1982; 9: 411-423.

54 Cole TJ. Secular trends in growth. Proc Nutr Soc 2000; 59: 317-324. 